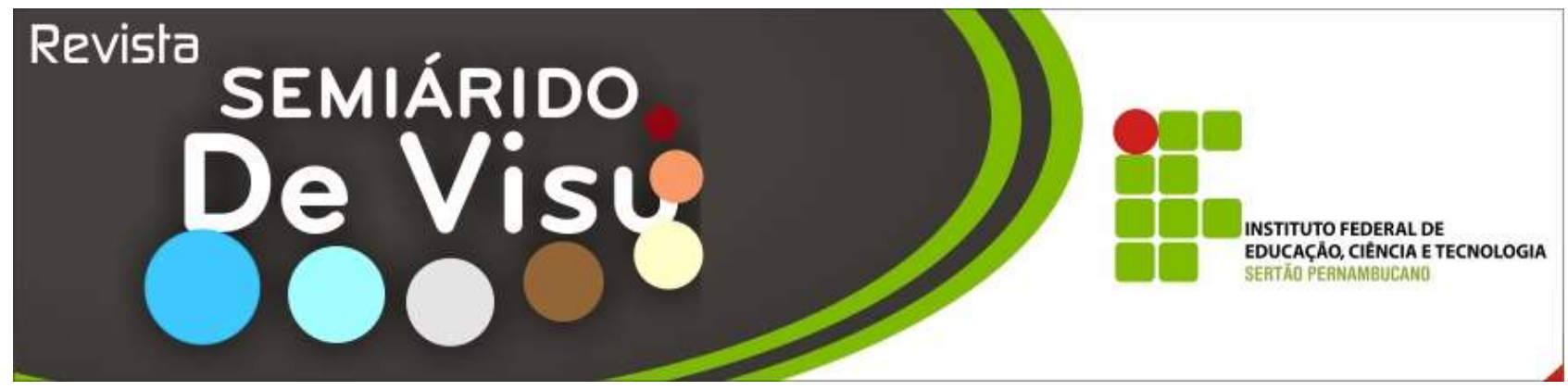

\title{
O uso do Edmodo como ferramenta educacional nas aulas de língua espanhola
}

\author{
Kélvya Freitas Abreu ${ }^{1}$, Francisco Kelsen de Oliveira ${ }^{2}$. \\ 1,2 Instituto Federal de Educação, Ciência e Tecnologia do Sertão Pernambucano - campus Salgueiro. BR 232, Km 508, \\ sentido Recife, Zona Rural - Salgueiro - PE - Brasil. CEP: 56.000-000 / Telefone: (87) 3421.0050 / E-mail: \\ ${ }^{1}$ kelvya.freitas@ifsertao-pe.edu.br; ${ }^{2}$ francisco.oliveira@ifsertao-pe.edu.br
}

\begin{abstract}
RESUMO: No Brasil, o uso das redes sociais chama atenção, já que o número de usuários chega a superar o de países com maior nível de inclusão digital. Todavia, o uso das redes sociais é lembrado com viés de entretenimento, sendo muitas vezes proibido em instituições de ensino e ambiente de trabalho, deixando de lado o seu potencial educativo. Nesse contexto, sugere-se a utilização de redes sociais educacionais (RSE), tais como o Edmodo, para que docentes criem seus cursos na Internet sem a necessidade de instalar e configurar servidores de hospedagem e aplicações para fornecer conteúdos (OLIVEIRA, 2010). Dessa forma, este artigo objetiva a apresentação dos resultados de experiência realizada com alunos do curso Espanhol básico, através do Edmodo. Usou-se da pesquisa exploratória e descritiva como metodologia para aferição das realizações feitas por alunos e docente através da referida ferramenta. Portanto, conclui-se que o uso do Edmodo e a integração com as diversas ferramentas utilizadas nos processos de ensino e de aprendizagem podem beneficiar docentes, discentes a usarem esta RSE.
\end{abstract}

Palavras-chave: Redes sociais educacionais; Internet; Ensino de língua.

\section{The use of Edmodo as an educational tool in Spanish Language Classes}

\begin{abstract}
In Brazil, the use of social networking draws attention, as the number of users will even surpass that of countries with the highest level of digital inclusion. However, the use of social networks is remembered biased entertainment, often banned in educational institutions and the workplace, leaving aside their educational potential. In this context, we suggest the use of social networking Educational (SNE), such as Edmodo for teachers to create their courses on the Internet without the need to install and configure servers hosting applications and provide content (OLIVEIRA, 2010). Thus, the research aims to present the results of experiment conducted with students of basic Spanish through Edmodo. It used the exploratory and descriptive research as a methodology for measuring the achievements made by students and faculty through that tool. Therefore, it is concluded that the use of Edmodo and integration with the various tools used in the teaching and learning can benefit teachers, students to use this SNE.
\end{abstract}

key words: Educational social networks. Internet. Language Teaching. 


\section{Introdução}

o longo dos últimos anos, a
sociedade vem se baseando em
transformações estruturais nas
relações econômicas, produtivas, tecnológicas e comunicativas. O principal modelo que surge se denomina como Sociedade da Informação e do Conhecimento, pelo qual os usuários, protagonistas de uma nova cultura, interagem e inovam pelos elos criados por meio de espaço e tempo diferenciados ao sistematizarem novas formas de aprendizagem, de ensino, de trabalho, de comunicação, modificando, portanto, o cotidiano das pessoas.

Deste modo, as Tecnologias da Informação e Comunicação (TIC), aliadas ao conhecimento consumido e produzido, tornamse base dessa nova sociedade. Hoje as TIC's são utilizadas para comunicação por meio de email, torpedos e mensagens em redes sociais, bem como se utilizam de diversos softwares para agregar funções aos Computadores Pessoais (PC), notebooks e netbooks, que estejam instalados em nossas máquinas ou hospedados em algum servidor na grande rede de computadores.

Almeida (2003, p. 329) enfatiza justamente que "a integração entre a tecnologia digital com os recursos da telecomunicação, que originou a internet, evidenciou possibilidades de ampliar o acesso à educação". É diante deste cenário que o presente estudo surge, tratando de aliar as possibilidades educativas que as TIC's nos proporcionam por meio de uma rede social educacional ao pensar no contexto do curso de espanhol implementado na modalidade Formação Inicial e Continuada (FIC) do campus Salgueiro no Instituto Federal de Educação, Ciência e Tecnologia do Sertão Pernambucano (IF Sertão-PE). Logo, o propósito era de criar outro espaço de interação em língua estrangeira para que os alunos atuassem. A seguir esboçam-se o referencial teórico que sustenta o estudo e a experiência com a rede social educacional (RSE) Edmodo.

Uma RSE pode ser compreendida como um ambiente de interação entre pessoas e organizações que permite a potencialização da aprendizagem através da utilização de ferramentas específicas para finalidade educacional, de modo a facilitar o controle das ações pelo docente, bem como permitir guardar um histórico dos diálogos, materiais e conteúdos trabalhados.

\section{Redes sociais e ensino}

Os investimentos feitos na educação brasileira nos últimos anos, principalmente após a publicação da Lei de Diretrizes e Bases da Educação Nacional (LDBEN, BRASIL, 1996), ainda não condizem com os resultados esperados dos alunos. Tal cenário se revela nas análises dos dados das avaliações de larga escala promovidas pelos Governos Estadual e Federal (Provinha Brasil, SPAECE, ENEM, ENADE, entre outros). As avaliações revelam dados preocupantes, principalmente, nas disciplinas de Português e Matemática dos alunos da Educação Básica.

Deste modo, o Ministério da Educação (MEC) vem, através da publicação de documentos governamentais, como os Parâmetros Nacionais do Ensino Médio (PCN, BRASIL, 1998), PCN em Debate (BRASIL, 2004) e as Orientações Curriculares Nacionais do Ensino Médio (OCNEM, BRASIL 2006), sugerir modificações nas práticas de ensino e de aprendizagem no contexto escolar, uma vez que é possível perceber que os alunos estão sendo aprovados, mas ainda com deficiências de leitura, escrita e interpretação de textos, ou seja, estão em uma etapa do ensino, mas na verdade o conhecimento é referente a uma etapa anterior.

As causas para esse problema são as mais variadas possíveis. No entanto, Abreu (2011) e Oliveira (2010) sinalizam como um dos principais fatores o ensino descontextualizado e memorístico nas práticas escolares, além do distanciamento do cotidiano do aluno, transformando o ato de aprender como atividades isoladas diante das diversas disciplinas do saber. Ou seja, não se aliam 
perspectivas interdisciplinares no momento da construção da aprendizagem.

Logo, o intuito é pensar a escola como espaço de formação e constituição do sujeito, devendo-se compreender que essa também possibilita através do estudo da linguagem "a formação de cidadania, a formação ética, o desenvolvimento da autonomia intelectual e o pensamento crítico" (ABREU, 2011, p.16), conforme considerado nas orientações governamentais.

Vale ressaltar que de acordo com Demo (2010, p.29):

[...] ao incentivar os alunos a refletirem e a se posicionarem como sujeitos ativos na interação com a linguagem, contribui-se para 'saber pensar' não reduzindo a aspectos como 'apenas arrumar, ordenar, formalizar ideias, mas principalmente desconstruilas, desarrumá-las e invectivá-las'.

Já segundo Moran (2007, p.8), “saber pensar, escolher, comparar e produzir novas sínteses, individualmente e em grupo, é fundamental para ter chances na nova sociedade que estamos construindo". Para o autor, parte-se da premissa que não aprendemos ou nos educamos somente em um período de tempo, mas ao longo de toda uma vida por meio das interações comunicativas que fazemos no nosso cotidiano.

Assim, ampliar os espaços educativos para além do muro escolar e conscientizar os discentes das mais variadas formas de aprendizagem é um dos objetivos deste estudo. Porém, será enfocado nesta investigação o aspecto que consiste no uso das TIC's como meio de dinamizar e oportunizar a aprendizagem, transpassando certas dificuldades.

Cumpre destacar que segundo Oliveira (2010), as escolas tornam-se os locais de acesso à tecnologia, pois os programas governamentais de inclusão digital oferecem equipamentos às escolas públicas, que receberam, nos últimos anos, PCs e impressoras para montagem dos laboratórios de informática educativa (LIE). Isso possibilita a realização de aulas mediadas por essas TICs, proporcionando aplicação de novos recursos pedagógicos que possam facilitar o aprendizado dos estudantes mediante a utilização de vídeos, animações, jogos e outros conteúdos interativos que consigam chamar e apreender a atenção dos estudantes, tornando o aprendizado prazeroso e natural, pois esse interagirá com o conhecimento por meio da ferramenta.

Conforme os Parâmetros Curriculares Nacionais do Ensino Médio - PCNEM (BRASIL, 1998), a utilização das TICs deve ser buscada pelos educadores como forma de possibilitar aos alunos o bom aprendizado, sob a perspectiva da realidade do mundo onde estão inseridos, assim como possibilitar a interdisciplinaridade com as demais ciências. Santana (2006) também aponta que o uso das TIC's deve ser estimulado pelos professores para agregar maior valor aos processos de ensino e de aprendizagem.

Assim, na área educacional, o uso das TICs possibilita o acesso de muitas pessoas a processos de aquisição de conhecimento e formação continuada, transformando justamente barreiras de espaço e de tempo ao rompê-las, já que locais muito distantes do Brasil, cujas condições de acesso a essas regiões são bastante difíceis ou até mesmo inacessíveis em alguns períodos do ano, possuem e têm disponíveis os mesmos recursos, anteriormente existentes apenas nos grandes centros urbanos e suas áreas limítrofes, com a qualidade garantida por Instituições de Ensino Superior (IES) de renome nacional.

Logo, de acordo com Castells (2003), na atualidade, a Internet é o tecido de vida das pessoas e de suma importância para a sociedade, tal como a eletricidade foi na Era Industrial. Segundo Oliveira (2010), isso mostra o grande valor da Internet para as atividades desenvolvidas na sociedade moderna, pois vários dos sistemas que se têm atualmente funcionam de maneira síncrona com servidores remotos de dados, provendo as solicitações aos usuários quase em tempo real.

Portanto, atualmente as TIC's reúnem as tecnologias e os métodos utilizados para captação, transmissão e distribuição das 
informações em formatos diversos (texto, som, vídeo, animações computacionais, etc.) para suportar a comunicação. Dessa forma, percebese o aumento do número de usuários da grande rede de computadores e de suas aplicações como redes sociais, no qual o Brasil se torna líder dentre os demais países em quantidade de clientes.

Deste modo, embora as redes sociais estejam intrinsecamente voltadas para o entretenimento, percebem-se possibilidades de trabalhos de cunho educacional, seja com a elaboração de atividades educativas com o uso das redes sociais mais conhecidas (Facebook, Twitter, Google+, entre outros) ou mesmo o uso de uma rede social educacional específica que possibilita não apenas a interação por parte do aluno, mas também entre docentes e os pais destes alunos.

Nessa perspectiva, é possível identificar várias pesquisas que envolvem softwares educativos, animações, simulações ou mesmo experiências com uso de páginas eletrônicas de conteúdos específicos e até com redes sociais já mencionadas (GOMES et al., 2011). Cumpre destacar que a mediação do professor e metodologia de trabalho adotada pelo educador torna possível uma aprendizagem colaborativa entre alunos em um ambiente costumeiramente visto pelos discentes exclusivamente para entretenimento.

Assim, nos últimos anos, tem-se visto a criação de redes sociais com finalidades específicas a fim de garantir a reunião de pessoas com interesses comuns e ainda aspectos específicos para os integrantes da referida rede social. O Linkedin é um exemplo de rede social destinada aos profissionais das mais diversas áreas que desejam estreitar laços entre outros pares da mesma área e entre as empresas. O Twitter, por sua vez, é um outro exemplo que foi criado como sendo um microblogging que garantisse $\mathrm{o}$ acesso às informações dos integrantes ao enviarem seus textos por meio de SMS até mesmo de celulares simples.

Contudo, como várias dessas redes não possuem ferramentas de controle e gerenciamento educacional pelo docente, o esforço deste profissional se torna maior para controlar as ações discentes em tais aplicações. Por isso o uso de RSE é mais viável porque já inclui ferramentas e aspectos destinados ao controle e trabalho dos docentes e discentes em uma ferramenta com recursos de apoio aos processos de ensino e aprendizagem.

Atualmente, há vários exemplos de RSE e com diversas especificidades para atender às várias necessidades e grupos, tendo como principal viés a educação:

- Edmodo: foi desenvolvido pelos mesmos mantenedores do Linkedin, está disponível em português, é gratuito e possui loja de aplicações educacionais.

- OpenRedu: é um exemplo open source genuinamente brasileiro e criado no Centro de Informática da Universidade Federal de Pernambuco (UFPE), está disponível em português e gratuito. Inclusive disponibiliza materiais e livros com experiências e exemplos de aplicações a serem utilizadas no ambiente. Isso possibilita já a capacitação dos docentes para que possam incluir a ferramenta em suas aulas de modo baseado em teorias pedagógicas ou mesmo adequar modelos pedagógicos à realidade educacional do docente.

- Teamie: não há versão em português e apenas o primeiro acesso é gratuito, sendo limitado para apresentação.

- Schoology: não há versão em português, mas o acesso é totalmente gratuito.

- Lore: está disponível apenas em inglês, gratuito e é voltado a estudantes de ensino superior.

- Passei Direto: é um exemplo brasileiro destinado a estudantes do ensino superior, mas impede o acesso direto, pois apenas libera depois dos alunos da instituição de ensino se cadastrarem.

- Ebah: é uma rede brasileira destinada ao compartilhamento de material acadêmico, cujos estudantes do ensino superior são o público-alvo. 
Após a análise das RSE citadas acima, o Edmodo foi escolhido por reunir características de uma rede social, aliadas às ferramentas voltadas ao trabalho docente, bem como a possibilidade de interação entre os participantes (alunos, pais de alunos e professores), como serão apresentados na seção seguinte.

\section{Material e métodos}

Ao vislumbrar as práticas educativas em torno da língua espanhola nos cursos de Formação Inicial e Continuada (Español básico - Turma comunidade interna e comunidade externa), tomou-se como ponto de partida o que se é sugerido nas OCNEM (BRASIL, 2006): "a aprendizagem de línguas não visa apenas objetivos instrumentais, mas faz parte da formação integral do aluno" e que "as linguagens [são] constituintes de significados e valores" (idem, 2006, p. 131), afirmando ser impossível dissociar os diferentes contatos entre culturas. Logo, a filosofia era que o "[...] processo educativo global desses estudantes, seria expô-los à alteridade, à diversidade, à heterogeneidade, caminho fértil para a construção da sua identidade" (idem, 2006, p. 129) na língua estrangeira.

Porém, muitos alunos reclamavam do pouco contato que tinham com a língua $\mathrm{e}$ solicitavam formas que os levassem a interagir em contextos extrassala por meio de conversas ou contato com outras leituras (entenda-se conhecimento cultural, por meio de textos, músicas, filmes). Assim, o processo de escolha da RSE, Edmodo, a ser utilizada na experiência levou em consideração a capacidade de alunos por turma sem pagamento de licença para uso que incluísse ferramentas básicas com fluxo de interação com texto, imagens e vídeos na própria mensagem. Além disso, buscaram-se ferramentas para criação de questionários objetivos, subjetivos e com ambos os modelos, de tal forma que fosse possível organizá-los por data de entrega a fim de que fosse criada uma agenda on-line de atividades, pois os alunos e a professora poderiam acompanhar as datas de entrega automaticamente.

Vale enfatizar que o Edmodo, portanto, é uma plataforma de rede social educativa de acesso livre baseada na tecnologia de microblogging, disponível em vários idiomas, inclusive o espanhol e o português, e com espaços customizados para a interação de professores, estudantes e parentes de estudantes.

Esta plataforma baseia-se em um modelo de aprendizagem colaborativa, o qual busca utilizar as mídias sociais como ferramenta para o gerenciamento do ensino e aprendizagem dos seus participantes, criando um ambiente de ensino personalizado para cada classe de usuário, conforme a Figura 1.

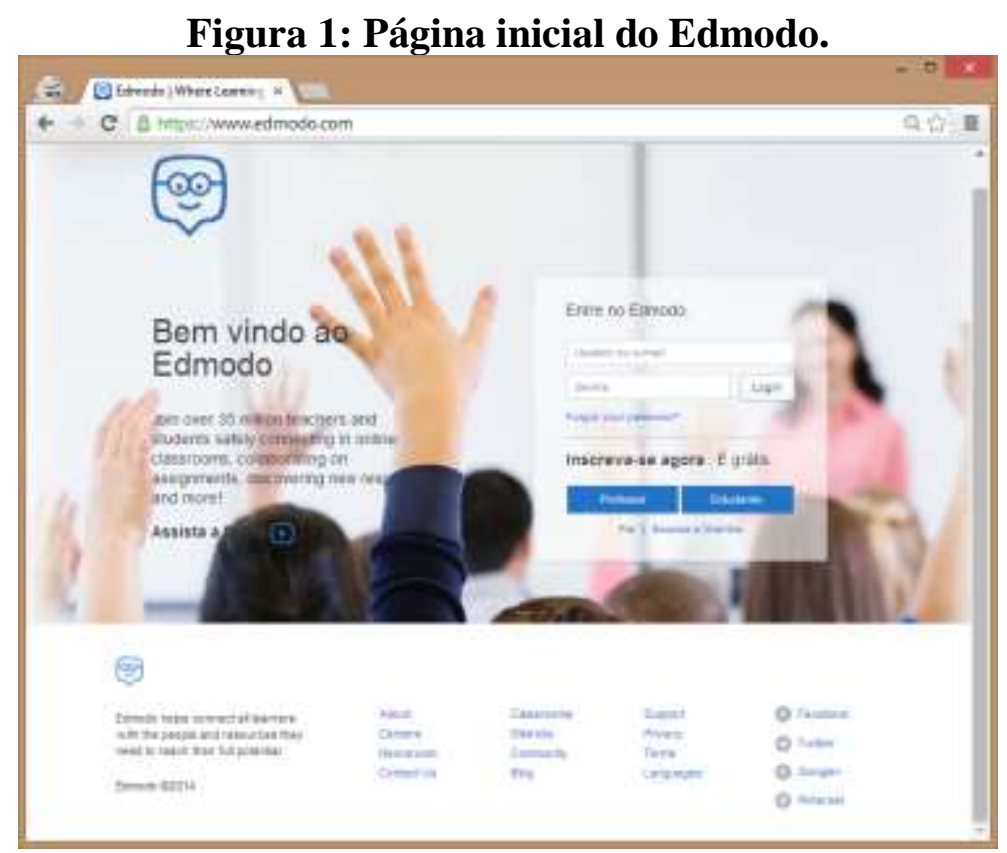

Fonte: (EDMODO, 2012) 
Assim, do total de 25 alunos matriculados nos cursos de Espanhol Básico (Espanhol comunidade interna: 15 discentes, e comunidade externa: 10 discentes), 22 adotaram a plataforma para o contato e forma de aprendizagem extrassala; os três alunos que não têm acesso à plataforma revelaram que não tinham interesse ou algumas vezes tinham dificuldades em utilizá-la.

As aulas extrassala eram dividas: Espanhol comunidade interna, nos dias de terça e quinta, com carga horária semanal de 5 horas/aulas. Espanhol comunidade externa, nos dias de segunda e quarta, com carga horária semanal de 5 horas/aulas.

Figura 2: Ferramentas avaliativas.

\begin{tabular}{|c|c|c|c|c|c|}
\hline 5 Nota & (1) Alerta & ( ) Tarea & (7) Prueba & Il. Encuesta & \\
\hline \multicolumn{2}{|c|}{ Titulo de la tarea } & & & Cargar tarea & Fecha Delimite \\
\hline
\end{tabular}

Fonte: (EDMODO, 2012).

Cumpre destacar que a plataforma Edmodo traz para o professor ferramentas de comunicação, (anotações e alertas) (ver Figura 2), e ferramentas avaliativas (tarefas, questionários de múltipla escolha e enquetes). Tais ferramentas foram utilizadas para a manutenção da aprendizagem dos conteúdos trabalhados em sala de aula ou mesmo pelo ambiente virtual.
Através das ferramentas avaliativas, pode-se propor atividades direcionadas a um ou mais grupos, estipulando data de entrega e duração de cada atividade. Junto às ações propostas, foram anexados arquivos ou links complementares, os quais serviram para a consulta dos estudantes durante a realização de uma dada atividade (ver Figura 3).

Figura 3: Fluxo central no Edmodo.

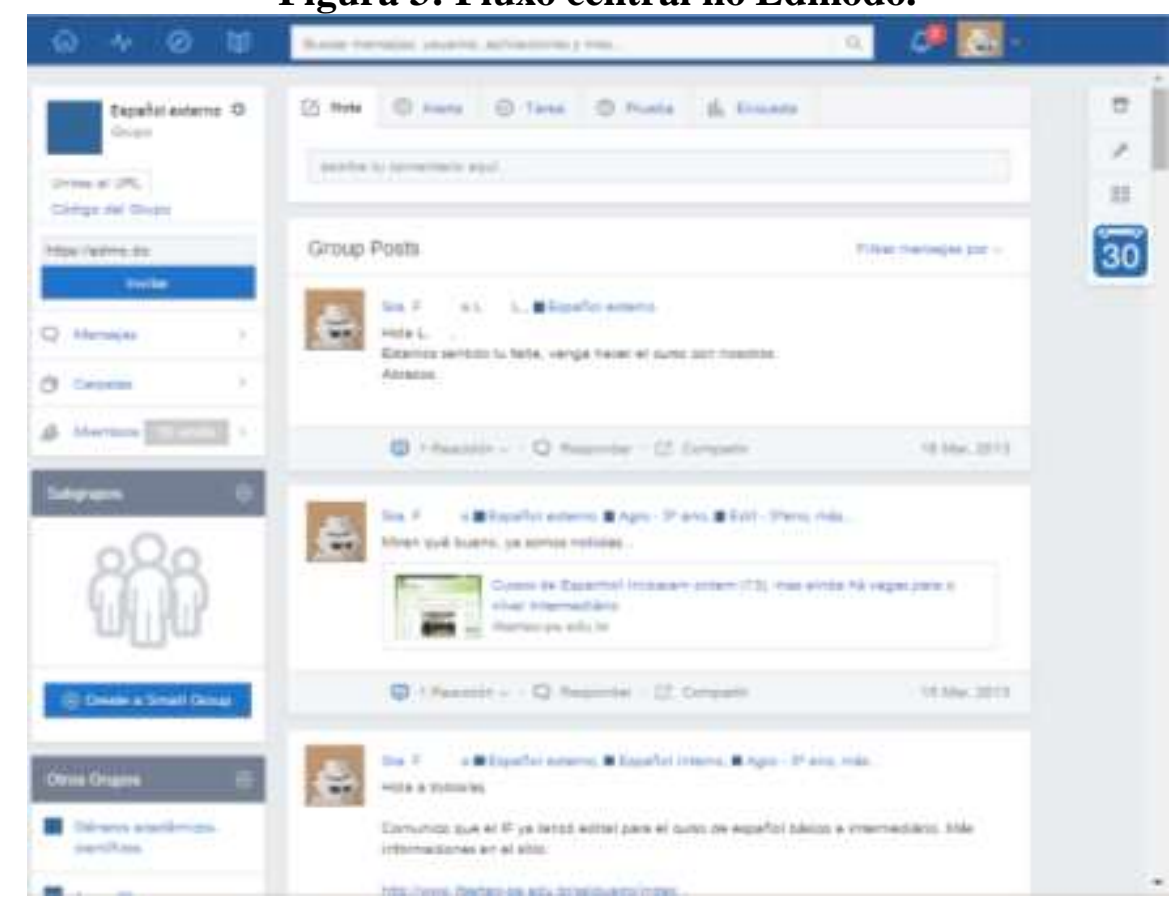

Fonte: (EDMODO, 2012). 
Outro ponto interessante foi utilizar as interações toda na língua alvo, no caso, o espanhol, inclusive nas trocas de e-mail. Vale destacar que além dos lembretes utilizados pela docente, o Edmodo fornece um sistema de notificação por e-mail e outro através da página do próprio ambiente, numa área chamada de notificações, para que o usuário possa acompanhar os eventos ocorridos, como pode ser visto através da Figura 3.

Os discentes, além das interações promovidas, quer seja através de questionários, simulados, postagens e conversação em espanhol, sugeriam temáticas e a docente acompanhava acrescentando na ferramenta Calendário uma data específica para abordar um dado assunto (Figura 4). Assim, esta ferramenta possibilitou estabelecer datas importantes para todos os seus grupos (classes) ou para um grupo em particular, existindo ainda as opções de imprimir e exportar tais datas.

\section{Figura 4: Calendário do Edmodo.}

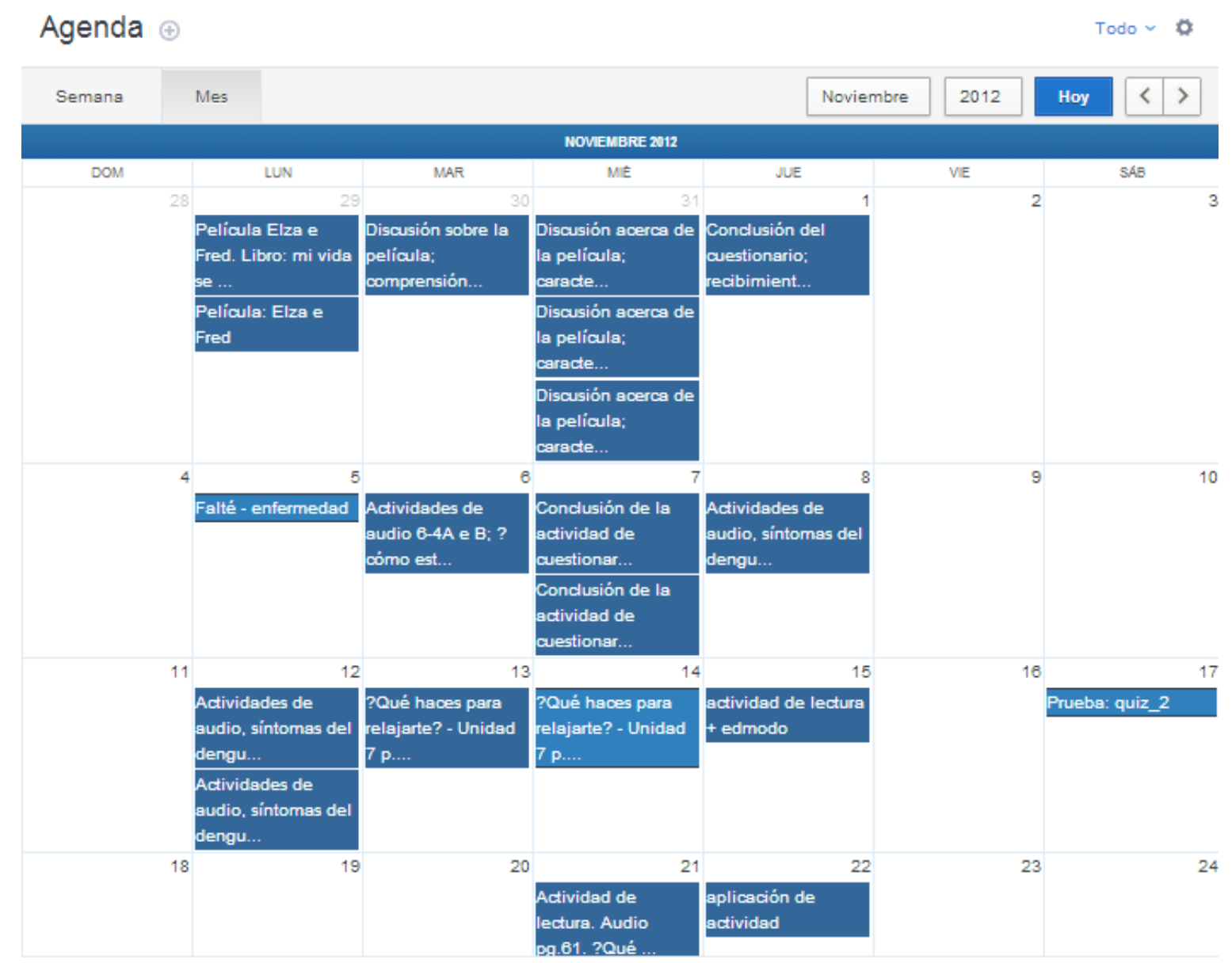

Fonte: (EDMODO, 2012).

$\mathrm{Na}$ área da Biblioteca (Figura 5), que serve para a organização e o gerenciamento dos conteúdos digitais disponibilizados para os estudantes, tanto a docente como os alunos puderam compartilhar materiais escritos ou multimídias, estando acessível a todos ou caso queira a um grupo específico, através de pastas próprias e com regras de acesso personalizadas.
A ferramenta também possibilitava o vínculo com documentos do Google Drive para que os estudantes tivessem acesso. O Google Drive é um pacote de produtos que permite armazenar, criar e editar diferentes tipos de documentos, trabalhar neles em tempo real com outras pessoas e armazená-los juntamente com outros arquivos: tudo feito on-line e gratuitamente. 
(ABREU; OLIVEIRA, 2015)

Figura 5: Biblioteca do Edmodo.

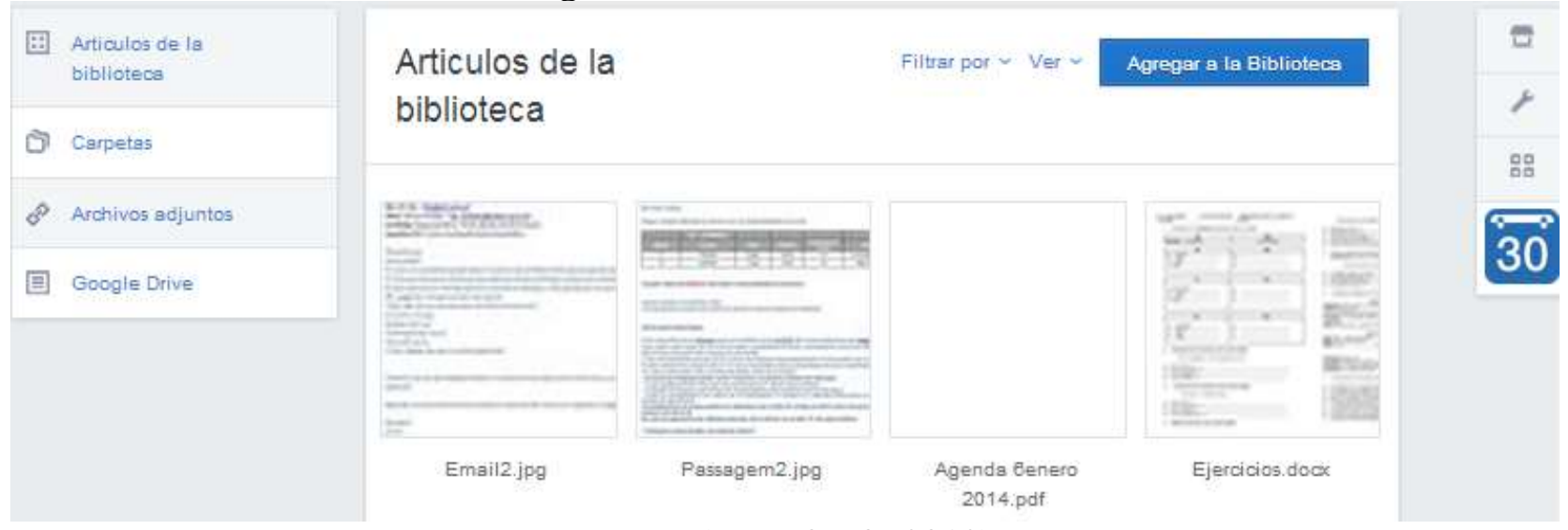

Fonte: (EDMODO, 2012).

Por fim, a ferramenta, por meio do Caderno de Notas (Figura 6), ofereceu o a possibilidade de acompanhamento da professora, no sentido de visualizar as notas e o desempenho obtido por cada aluno de um determinado grupo. Cada discente também podia ver a qualquer tempo o seu desempenho em uma atividade específica, facilitando o controle de notas. O interessante era que finalizada uma atividade, esta era discutida e debatida em sala de forma bastante produtiva, pois os alunos questionavam o porquê de não compreenderam dada expressão ou regra gramatical, nos exercícios de normatização da língua.

\section{Figura 6: Controle de notas do Edmodo.}

\section{Progress / Español interno}

Grades Badges

\begin{tabular}{|c|c|c|c|}
\hline [A] New Grade & & quile 2 & $\begin{array}{c}\text { Unbiled quiz } 2012 \\
10-20-05-07-50\end{array}$ \\
\hline Student & Total & & \\
\hline
\end{tabular}

\begin{tabular}{|c|c|c|c|}
\hline M & $60 \%$ & $6 / 10$ & - \\
\hline$J$ & $53 \%$ & $8 / 10$ & $0 / 5$ \\
\hline j & $0 \%$ & $=$ & - \\
\hline D & $80 \%$ & $8 / 10$ & - \\
\hline
\end{tabular}

Fonte: (EDMODO, 2012).

Deste modo, as características e recursos presentes no Edmodo o posicionam como a alternativa mais viável diante de outras plataformas de auxílio à aprendizagem, tendo em vista que a interação com sua interface lembra muito a da rede social Facebook (rede social que reúne pessoas a seus amigos e àqueles com quem trabalham, estudam $\mathrm{e}$ 
convivem). Os usuários demonstram uma grande facilidade no seu manuseio, de maneira que em pouco tempo conseguem interagir com a plataforma entre si e com professor de maneira satisfatória.

\section{Resultados e discussão}

A partir das ferramentas descritas anteriormente foi possível otimizar e dar suporte à disciplina presencial de espanhol básico, cujos alunos acompanhavam também o Edmodo com atividades e conteúdos auxiliares ao que era tratado durante as aulas em sala. Dessa forma, era possível elaborar questionários e debater assuntos levantados em sala de aula, tendo um momento extraclasse com acompanhamento da docente.

Durante a implantação do ambiente junto aos estudantes, outras características e recursos da plataforma puderam ser explorados, de maneira que potencializaram o interesse do alunado pelos conteúdos disponibilizados no ambiente do Edmodo, como inclusão de materiais na biblioteca sem apresentá-los prontamente aos alunos, bem como a união de hiperlinks para construir o conhecimento em espanhol.

Assim as atividades sugeridas aos alunos foram prontamente respondidas, sendo a inclusão da duração de realização do exercício um fator que gerou muitas questões equivocadas nas primeiras atividades, pois os alunos iniciavam logo a atividade para buscarem posteriormente os referidos assuntos a serem estudados. Além disso, alguns alunos não entregaram as suas atividades dentro do prazo previsto e pediram prorrogação do período de entrega, porém, o indeferimento da solicitação possibilitou a entrega dentro do prazo das atividades seguintes.

Outro fator positivo foram as análises das questões em sala de aula, que provocaram debates maiores entre todos os alunos presentes no dia seguinte ao prazo final de entrega, demonstrando que todos tiveram acesso ao questionário. Apesar das dificuldades no letramento digital de alguns desses alunos ao não terem acessado por completo o questionário foi possível existir a discussão (destaca-se que por meio do relatório gerado pela ferramenta, a docente pode visualizar as quantidades de questões respondidas corretamente ou não, a duração para resolução de cada uma das questões e o horário da sua realização).

Muitos estudantes que apresentam traços de timidez em sala de aula conseguiram externar algumas ideias e sentimentos através da interação com as ferramentas disponíveis no ambiente. Em relatos presenciais, tais alunos diziam estar gostando de utilizar a plataforma, visto que já possuíam familiaridade e prática em alguma das redes sociais anteriormente citadas.

\section{Conclusões}

Conforme exposto no decorrer deste artigo, o ambiente Edmodo foi inicialmente escolhido por possuir características que tornam sua utilização semelhante a de redes sociais de propósito geral, como Facebook, Twitter e Google+, as quais utilizam a tecnologia de postagem de mensagens de textos, imagens e vídeos como veículo de comunicação entre os seus participantes.

Portanto, com o auxílio da plataforma Edmodo, a professora de espanhol manteve um contato mais frequente com o alunado em contexto extrassala de aula, proporcionando um maior interesse pela disciplina, visto que o ambiente virtual possibilitou a utilização de um número grande de mídias e conteúdos. Além de acompanhamento no que tange à produção escrita do idioma e dos resultados dos simulados, bem como um levantamento do conhecimento adquirido por meio ainda de questionários.

Tal experiência elevou a confiança dos estudantes que participaram do curso de espanhol básico na modalidade de Formação Inicial e Continuada (FIC) do campus Salgueiro no IF Sertão-PE, uma vez que os próprios discentes sentiram a necessidade de produzir na língua-alvo, ou seja, em espanhol, e assim se motivaram em serem produtores do seu conhecimento ao se tornarem um pouco mais autônomo e ousados com relação ao uso da língua. No entanto, ainda há diversos 
aspectos da ferramenta que não foram traduzidos aos idiomas suportados, assim mesmo trabalhando em português ou espanhol ainda há termos em inglês.

\section{Referências}

ABREU, K. F.; BAPTISTA, L.M.T.R. O agir dos professores de espanhol no ensino a distância. In: $2^{\circ}$ Colóquio Nacional Sobre Hipertexto, 2011, Fortaleza. Anais do $2^{\circ}$ Colóquio Nacional Sobre Hipertexto. Fortaleza: Universidade Federal do Ceará, 2010. p. 32-38.

ALMEIDA, M.E.B. Educação a distância na internet: abordagens e contribuições dos ambientes digitais de aprendizagem. Educação e Pesquisa, São Paulo, v.29, n.2, p. 327-340, jul./dez. 2003.

BRASIL, Ministério da Educação - Secretaria de Educação Média e Tecnológica. Parâmetros Curriculares Nacionais: Ensino Médio - Ciências da Natureza, Matemática e suas tecnologias. Brasília: MEC/SEMTEC, 1998. Disponível em: http://portal.mec.gov.br/seb/arquivos/pdf/cienci an.pdf. Acesso em: 15 de dezembro de 2009.

Orientações Curriculares para o Ensino Médio: Linguagens, Códigos e suas Tecnologias. Brasília, Secretaria de Educação Básica, 2006. Disponível em: http://portal.mec.gov.br/seb/arquivos/pdf/book_ volume_01_internet.pdf. Acesso: em 02/12/09.

Instituto Nacional de Estudos e Pesquisas Educacionais Anísio Teixeira. Índice de Desenvolvimento da Educação Básica. Brasília: MEC, 2008. Disponível em: http://ideb.inep.gov.br/Site/. Acesso em: 15 de dezembro de 2011.

CASTELLS, M. A galáxia da Internet: reflexões, os negócios e a sociedade. Tradução: Maria Luiza X. de A. Borges. Rio de Janeiro: Jorge Zahar Ed. 2003.
D’AMBRÓSIO, U. Matemática, ensino e educação: uma proposta global. Temas \& Debates-SBEM, v. 4, n. 3, p. 1-16, 1991.

DEMO, P. Saber pensar é questionar. Brasília: Liber Livro, 2010.

EDMODO. Rede Social Educacional Edmodo. Disponível em: www.edmodo.com. Acesso em: 10 de agosto de 2012.

GOMES, A.S. [et al.]. Educar com o Redu. Recife: Redu Educational Technology, 2012.

GOMES A. S.; SOUZA, F. V. C.; ABREU, J. A. B.; LIMA L. C. C.; MELO, C. A.; PAIVA, G. L.; DUARTE, A. P. Colaboração, Comunicação e Aprendizagem em Rede Social Educativa, In: XAVIER A. C. (Ed.) Hipertexto e Cibercultura: links com a literatura, a publicidade, o plágio e as redes sociais educacionais. São Paulo: Respel, 2011.

MORAN, J.M. A educação que desejamos: Novos desafios e como chegar lá. Campinas, São Paulo: Papirus, 2007.

OLIVEIRA, F.K. O vídeo pela Internet como ferramenta educacional no ensino da Geometria. 2010. 102f. Dissertação (Programa de Pós-Graduação em Ciências da Computação) - UECE, Fortaleza, 2010.

PONTES, M.G.O. Medidas e proporcionalidade na escola e no mundo do trabalho. João Pessoa: Ideia, 2009.

SANTANA, J.R. Educação matemática: favorecendo investigações matemáticas através do computador. 2006. 430f. Tese (Programa de Pós-Graduação em Educação Brasileira) UFC, Fortaleza, 2006. 